\title{
Should We Wear Masks While Exercising Outdoor During COVID-19?
}

\author{
Young Sub Kwon \\ Humboldt State University
}

\section{Overview}

While safety is a high priority for our community during the Covid-19 pandemic, exercise is essential to improve and maintain a healthy lifestyle (ACSM, 2018). Fitness centers are reopening across the county with various safety precautions including masks and social distancing. Although the Centers for Disease Control and Prevention (CDC, 2020) recommends all people to wear a mask (except for children younger than 2 years old, anyone who has trouble breathing, and anyone who is unconscious, incapacitated, or otherwise unable to remove the cloth facecovering without assistance), wearing a mask may not be possible in every situation. For example, during outdoor exercises, wearing a mask contributes to issues of potential breathing restrictions (lower the oxygen gas concentration levels in the recirculated air). This column concerns views on wearing masks while exercising, especially when doing it outdoors.

Keywords: COVID-19, mask, Centers for Disease Control and Prevention (CDC)

\section{Article History}

Received 11 September 2020

Accepted 30 September 2020

Published 31 October 2020

Available online 31 December 2020

https://doi.org/10.47544/johsk.2020.1.1.35

Corresponding Author
Young Sub Kwon
Young.Kwon@humboldt.edu
Department of Kinesiology \& Recreation Administration
College of Professional Studies
Humboldt State University, USA

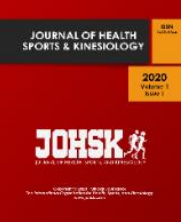

The World Health Organization (WHO, 2020) recommends people not wear masks while exercising on June 16, 2020. According to the WHO, "sweat can make the mask become wet more quickly which makes it difficult to breathe and promotes the growth of microorganisms. The important preventive measure during exercise is to maintain physical distance of at least one meter from others."

The CDC recommends on July 16,2020, all people 2 years of age and older wear a cloth face covering (or a mask) in public settings and when around people who don't live in your household, especially when other social distancing measures are difficult to maintain. The CDC recognizes that wearing cloth face-coverings may not be possible in every situation or for some people. "People who are engaged in high intensity activities, like running, may not be able to wear a cloth face covering if it causes difficulty breathing. If unable to wear a cloth face covering, consider conducting the activity in a location with greater ventilation and air exchange (for instance, outdoors versus indoors) and where it is possible to maintain physical distance from others."

\section{Journal of Health Sports \& Kinesiology | ISSN 2692-9864 | www.johsk.com}


| 2020 | Volume 1 | Issue 1 | The Journal of Health, Sports, and Kinesiology |

The largest state by population in US, California has started requiring people throughout the state to wear masks in most indoor settings and outdoors when distancing isn't possible as the coronavirus continues to spread on June 18, 2020; however, it includes several exceptions, including outdoor recreation and exercise such as walking, hiking, running, or bicycling. But if people doing such activities can't stay six feet ( 1.8 meters) apart from others, the state orders they should wear masks (Ronayne \& Taxin, 2020).

The Central Disease Control Headquarters (Korea Centers for Disease Control \& Prevention, KCDC) announced on June 22, 2020, that "although mask wearing is important for COVID-19 prevention, wearing masks in a high-heat outdoor environment may cause serious physical stress such as rise in heart rate, respiration rate, and body temperature. Therefore, masks are not recommended in outdoor environments where it is possible to maintain 2 meters or more of physical distance from other people."

However, mandatory wearing of masks or face-coverings in Covid-19 observed in some countries coincides with a reduction in rates of transmission (Greenhalgh, 2020), and more countries are making masks mandatory (O'Grady, 2020; Ingraham, 2020).

British Journal of Sports Medicine (BMJ) released their guidance on June 12, 2020, (Blanco \& Rensburg, 2020) that people should wear a face mask during an outdoor exercise session, and BMJ also clearly mentioned issues of potential breathing restriction and discomfort in mind. The BMJ recommended practicalities of wearing a face mask during exercise include (1) securing the face-covering in a comfortable manner before leaving the house, (2) maintaining social distancing during exercise, (3) sanitizing by taking along travel-sized sanitizers in a pocket, (4) exercising at a lower intensity than usual while wearing a mask, (5) avoiding touching face during exercise, and (6) taking a second mask along during exercise sessions for replacement.

According to the WHO and the CDC, people should not wear masks while exercising, but the BMJ recommends people wear a face mask during exercise with some guidance.

\section{Summary}

- You need to consider both the benefits of wearing a mask, its adverse effect on performance and health during exercise, and the absence of evidence-based research regarding the effect of the use of a mask during exercise.

- If you follow the guidelines of either the WHO of the CDC, you must maintain physical distance of at least one meter (WHO) or 1.8 meters (CDC, https://www.cdc.gov/coronavirus/2019-ncov/daily-lifecoping/personal-social-activities.html) from others during exercise.

- If you follow the guidelines of BMJ, you must follow BMJ's recommended practicalities aforementioned.

- Lastly, if you have cardiovascular, respiratory, or metabolic conditions, you must consult your physician before attempting exercise while wearing a mask.

Disclaimer: This content including advice provides generic information only. It is in no way a substitute for a qualified medical opinion. Always consult your physician and your specialist for more information. IOHSK does not claim responsibility for this information.

\section{References}

Blanco, J. H., \& Rensburg, D. C. (2020, June 15). Should people wear a face mask during exercise: What should clinicians advise? Retrieved July 27, 2020, from https://blogs.bmj.com/bjsm/2020/06/12/should-people-weara-face-mask-during-exercise-what-should-clinicians-advise/

COVID-19: Considerations for Wearing Cloth Face Coverings. (n.d.). Retrieved July 27, 2020, from https://www.cdc.gov/coronavirus/2019-ncov/prevent-getting-sick/cloth-face-cover-guidance.html

FACT: People should NOT wear masks while exercising. (2020, June 16). Retrieved July 27, 2020, from https://www.who.int/emergencies/diseases/novel-coronavirus-2019/advice-for-public/myth-busters

Greenhalgh, T. (2020, May 26). Face coverings for the public: Laying straw men to rest. Retrieved July 27, 2020, from https://onlinelibrary.wiley.com/doi/10.1111/jep.13415

Journal of Health Sports \& Kinesiology | ISSN 2692-9864 | www.johsk.com 
| 2020 | Volume 1 | Issue 1 | The Journal of Health, Sports, and Kinesiology |

Ingraham, C. (2020, June 30). National mask mandate could save 5 percent of GDP, economists say. Retrieved July 27, 2020, from https://www.washingtonpost.com/business/2020/06/30/mask-mandate-gdp-economygoldman-sachs/

Korea Centers for Disease Control \& Prevention. (2020, June 22). Press Release: News Room. Retrieved July 27, 2020, from https://www.cdc.go.kr/board/board.es?mid=a30402000000

O'Grady, S. (2020, July 20). Unlike the United States, more and more countries are making masks mandatory. Retrieved July 27, 2020, from https://www.washingtonpost.com/world/2020/07/20/mandatory-face-maskrequirements-global-coronavirus/

Riebe, D., Ehrman, J. K., Liguori, G., \& Magal, M. (2018). ACSM's guidelines for exercise testing and prescription. Philadelphia: Wolters Kluwer.

Ronayne, K., \& Taxin, A. (2020, June 18). California orders people to wear masks in most indoor spaces. Retrieved July 27, 2020, from https://abcnews.go.com/Health/wireStory/california-orders-people-wear-masks-indoorspaces-71327757

(C) 2020. This work is licensed under a CC BY-NC-SA 4.0 International license.

This is an open access article distributed under the Creative Commons Attribution License which permits unrestricted use, distribution, and reproduction in any medium, provided the original work is properly cited.

\section{Journal of Health Sports \& Kinesiology | ISSN 2692-9864 | www.johsk.com}

